\title{
A phase I dose-escalation study to a predefined dose of a transforming growth factor- $\beta 1$ monoclonal antibody (T/M1) in patients with metastatic cancer
}

\author{
ALLEN COHN $^{1}$, MICHAEL M. LAHN ${ }^{2}$, KRISTEN E. WILLIAMS ${ }^{2}$, ANN L. CLEVERLY ${ }^{3}$, \\ CELINE PITOU $^{3}$, SUNIL K. KADAM ${ }^{2}$, MARK W. FARMEN ${ }^{2}$, DURISALA DESAIAH ${ }^{2}$, \\ ROBERT RAJU $^{4}$, PAUL CONKLING ${ }^{5}$ and DONALD RICHARDS ${ }^{6}$ \\ ${ }^{1}$ Rocky Mountain Cancer Center - Midtown, Denver, CO; ${ }^{2}$ Eli Lilly and Company, Indianapolis, IN, USA; \\ ${ }^{3}$ Eli Lilly and Company, Erl Wood Manor, Windlesham, Surrey, UK; ${ }^{4}$ Innovation Center Kettering Medical Center, \\ Kettering, OH; ${ }^{5}$ Virginia Oncology Associates, Norfolk, VA; ${ }^{6}$ Tyler Cancer Center, Tyler, TX, USA
}

Received April 3, 2014; Accepted May 5, 2014

DOI: 10.3892/ijo.2014.2679

\begin{abstract}
Transforming growth factor $\beta$ (TGF- $\beta$ ) plays an important role in cancer. Monoclonal antibodies (mAb) designed to specifically block the TGF- $\beta$ ligands, are expected to inhibit tumor progression in patients with metastatic cancer. T $\beta \mathrm{M} 1$ is a humanized $\mathrm{mAb}$ optimized for neutralizing activity against TGF- $\beta 1$. The objective of this clinical trial was to assess the safety and tolerability of T $\beta \mathrm{M} 1$ in patients with metastatic cancer. In this phase I, uncontrolled, non-randomized, dose-escalation study, 18 eligible adult patients who had measurable disease per RECIST and a performance status of $\leq 2$ on the ECOG scale were administered T $\beta \mathrm{M} 1$ intravenously over $10 \mathrm{~min}$ at doses of $20,60,120$ and $240 \mathrm{mg}$ on day 1 of each 28-day cycle. Safety was assessed by adverse events (as defined by CTCAE version 3.0) and possible relationship to study drug, dose-limiting toxicities and laboratory changes. Systemic drug exposure and pharmacodynamic (PD) parameters were assessed. T $\beta$ M1 was safe when administered once monthly. The pharmacokinetic (PK) profile was consistent with a mAb with a mean elimination half-life approximately 9 days. Although anticipated changes in PD markers such as serum VEGF, bFGF and mRNA expression of SMAD7 were observed in whole-blood, suggesting activity of T $\beta \mathrm{M} 1$ on the targeted pathway, these changes were not consistent to represent a PD effect. Additionally, despite the presence of an activated TGF- $\beta 1$ expression signature in patients'
\end{abstract}

Correspondence to: Dr Michael M. Lahn, Lilly Research Laboratories, Eli Lilly and Company, Indianapolis, IN 46285, USA E-mail: mlahn@lilly.com

Key words: metastatic cancer, monoclonal antibody inhibitor $\mathrm{T} \beta \mathrm{M} 1$, pharmacodynamic and pharmacokinetic parameters, safety, transforming growth factor- $\beta 1$ whole blood, the short dosing duration did not translate into significant antitumor effect in the small number of patients investigated in this study.

\section{Introduction}

Transforming growth factor $\beta$ (TGF- $\beta$ ) comprises 3 specific isoforms $(-\beta 1,-\beta 2$ and $-\beta 3)$ that are part of the TGF- $\beta$ super family. These cytokines regulate diverse biological functions including cell proliferation, differentiation, motility, survival and apoptosis (1). The role of TGF- $\beta$ in tumor biology is complex because it can act as both a tumor suppressor and a tumor promoter $(2,3)$. TGF- $\beta$ functions as a tumor suppressor by inhibiting cell growth in normal tissues, particularly in epithelial and lymphoid tissues (3). However, in the tumor cells it acts as an autocrine growth factor, creating an angiogenic, local immunosuppressive environment that enhances tumor growth and aggravates the invasive and metastatic tumor-cell behavior (4). The dual and opposing functions of TGF- $\beta$, including its ability to activate signaling molecules (5) other than the canonical SMAD pathway (6), has been implicated in the growth of a variety of human tumors, such as prostate, colon, breast, gastric, liver, renal and melanoma (7). Elevated plasma TGF- $\beta 1$ concentration, the most prevalent TGF- $\beta$ isoform in the systemic circulation in patients with invasive metastatic disease, are correlated with adverse outcomes (8-22).

Three approaches to inhibit the TGF- $\beta$ pathway have been investigated, including the use of antisense oligonucleotides (ASOs), neutralizing monoclonal antibodies (mAb) against ligand-receptor interactions, and inhibitors of TGF- $\beta$ receptor I kinases against the receptor-mediated signaling cascade. Though ASOs are highly specific inhibitors of TGF- $\beta$ (23), they are limited by their organ and tissue penetration (24). The small-molecule kinase inhibitors $(25,26)$, despite their advantages of high pathway selectivity and oral administration, are liable to cause toxicity and the cause of this toxicity is under investigation (27). The mAbs, designed specifically to block active TGF- $\beta$ ligands and 
prevent their interaction with the type II receptor (28), are expected to inhibit tumor progression in patients with metastatic cancer (28). This concept has been tested in animal models using neutralization of TGF- $\beta$ with mAbs $(29,30)$. For example, the systemic and transgenic administration of the soluble TGF- $\beta$ RII/Fc dimer that binds all 3 TGF- $\beta$ isoforms, reduced the tumor burden as well as intravasation and metastasis in tumor animal models and in transgenic breast cancer mammary tumor virus (MMTV)-neu mice models, respectively (29).

$\mathrm{T} \beta \mathrm{M} 1$ is a humanized mAb highly selective for neutralizing only active TGF- $\beta 1$. Studies on the $4 \mathrm{~T} 1 \mathrm{Balb} / \mathrm{c}$ mice model demonstrated antitumor activity for both TGF- $\beta 1$-specific mouse surrogate $\mathrm{mAb}$ and -neutralizing $\mathrm{mAb} 1 \mathrm{D} 11$ that neutralizes all 3 isoforms. The primary objective of this phase I clinical trial was to assess the safety and tolerability of T $\beta \mathrm{M} 1$ administered as monthly intravenous monotherapy in patients with metastatic cancer. The tested dose range of T $\beta \mathrm{M} 1$ was chosen to provide systemic $\mathrm{T} \beta \mathrm{M} 1$ exposure predicted to have antitumor effects based on murine surrogate $\mathrm{mAb}$ data efficacy in a mouse model in vivo. Secondary objectives were to assess T $\beta \mathrm{M} 1$ systemic exposure and explore pharmacodynamic (PD) markers in whole blood by measuring global and specific changes in the expression of genes known to be associated with TGF- $\beta$ pathway activation $(29,31)$.

\section{Materials and methods}

Antibody. T $\beta \mathrm{M} 1$ is an IgG4 mAb with a preferential binding affinity to active TGF- $\beta 1$. The in vitro ligand binding properties of $\mathrm{T} \beta \mathrm{M} 1$ were determined using surface plasma resonance (SPR) to assess the binding specificity of the antibody to the 3 TGF- $\beta$ ligands. T $\beta$ M1 showed no binding to TGF- $\beta 2$ and greater than 700 -fold selectivity for TGF- $\beta 1$ over TGF- $\beta 3$.

Dose selection. One rat $\mathrm{PK} / \mathrm{PD}$ study was performed in 13762 (mammary carcinoma) syngeneic model with T $\beta \mathrm{M} 1$ at different dose levels. This was used to establish the $\mathrm{EC}_{50}$ value based on the SMAD2 phosphorylation in tumors. The choice of the doses was decided after a review of the preclinical package (rat PK/PD data with T $\beta \mathrm{M} 1$ and mouse efficacy data with the surrogate antibody), and animal toxicology data. The intravenous dose range of 20 to $240 \mathrm{mg}$ was expected to be safe. Because T $\beta$ M1 binds to active TGF- $\beta 1$ at low concentrations, it was projected that doses of 120 and $240 \mathrm{mg}$ would provide sufficient TGF- $\beta 1$ blockade in cancer patients as assessed by systemic PD effects. Hence, the PD effects were expected to translate to clinical signals, such as tumor responses. This more focused approach for TGF- $\beta$ inhibition may provide safety advantages over the non-selective-TGF- $\beta$ $\mathrm{mAb}$ fresolimumab $(32,33)$ which has produced antitumor responses in patients with melanoma and renal cell carcinoma (RCC) at similar doses.

Study design. This was a phase I, multicenter open-label, uncontrolled, non-randomized, dose-escalation study of intravenously (IV) administered T $\beta \mathrm{M} 1$ in patients with metastatic cancer for whom no treatment of higher priority existed.
At least 3 patients were enrolled in 1 of 4 cohorts receiving T $\beta$ M1 flat doses of 20, 60, 120 and $240 \mathrm{mg}$, respectively, on day 1 of each 28-day cycle. Dose escalation to the next cohort proceeded only after 3 patients completed 1 treatment cycle without a dose-limiting toxicity (DLT) and after careful assessment of serum drug concentration and safety information. Hematologic or non-hematologic toxicity with a grade $\geq 3$ was considered as a DLT in patients treated with the study medication at different dose levels according to the National Cancer Institute (NCI) and the Common Terminology Criteria for Adverse Events (CTCAE), version 3.0.

Patients. Adult patients who provided written informed consent and had a histologic or cytologic diagnosis of cancer for which no proven effective therapy existed were included in the study. Eligible patients were required to have disease that was measurable or nonmeasurable as defined by the Response Evaluation Criteria in Solid Tumors (RECIST) and to have a performance status of $\leq 2$ on the Eastern Cooperative Oncology Group (ECOG) scale. Patients were required to have adequate hematologic, hepatic, and renal functions and to have discontinued all previous therapies for cancer at least 4 weeks prior to study enrolment.

Exclusion criteria included medically uncontrolled cardiovascular illness, electrocardiogram anomalies, history of gastrointestinal (GI) bleeding, significant hemoptysis, hematuria within 3 months prior to study entry, serious pre-existing medical conditions (at the discretion of the investigator), unhealed wounds, history of autoimmune disease, symptomatic central nervous system (CNS) primary or metastatic malignancy, CNS active infection, human immunodeficiency virus (HIV), hepatitis, or immunosuppressive disease or hematological malignancies.

Treatment. Lyophilized T $\beta$ M1 at all doses $(20,60,120$ and $240 \mathrm{mg}$ ) was reconstituted in saline and administered as a 10 -ml IV infusion via infusion pump at $10 \mathrm{ml}$ per $10 \mathrm{~min}$ on day 1 of each 28-day cycle. Patients were monitored for any signs or symptoms of allergic reactions for at least $1 \mathrm{~h}$ after the administration of the study drug. No dose adjustments or reductions were allowed.

Safety analysis. Safety was evaluated in patients who received at least one dose of T $\beta \mathrm{M} 1$. Safety assessment was based on the summaries of adverse events including severity (as defined by CTCAE version 3.0) and possible relationship to the study drug, DLTs and laboratory changes at each dose level. Safety was also analyzed by bone pain (level of pain and location) assessment, oral examination of the gingiva (to detect hyperplasia), skin assessment, evaluation of ECOG performance status, electrocardiogram (ECG), and echocardiography/Doppler. Clinically significant abnormal results were recorded as adverse events. Standard laboratory tests including chemistry, hematology and urinalysis panels were also performed. All concomitant medications were documented throughout the patient's participation in the study.

Efficacy analysis. Data on any clinical benefit and tumor response were tabulated. No formal efficacy analysis was performed. 
Bioanalytical methods. A validated enzyme-linked immunosorbent assay (ELISA) method (ALTA Analytical Laboratory, San Diego, CA, USA) was used to analyze the human serum samples for T $\beta \mathrm{M} 1$. The lower and upper limits of quantification were 7.5 and $90.0 \mathrm{ng} / \mathrm{ml}$, respectively. In order to yield results within the calibrated range, samples above the limit of quantification were diluted and reanalyzed. During validation, the inter-assay accuracy ( $\%$ relative error) ranged from $-13.5 \%$ to $2.0 \%$ while the inter-assay precision (\% relative standard deviation) ranged from 12.5 to $13.4 \%$. T $\beta \mathrm{M} 1$ was stable for up to 365 days when stored at approximately $-70^{\circ} \mathrm{C}$.

Pharmacokinetic (PK) methods. All patients who received at least one dose of T $\beta \mathrm{M} 1$ and had serum samples collected were subject to pharmacokinetic analyses. The PK parameters, area under the concentration-time curve (AUC) and half-life for T $\beta$ M1 were computed by standard noncompartmental methods of analysis using Win Nonlin Professional Edition (version 5.3) on a computer that met or exceeded the minimum system requirements for this program with appropriate and validated software. The extent of dose proportionality was assessed using estimated AUC. AUC estimates were log-transformed prior to analysis and ratios of dose-normalized geometric means and the corresponding $90 \%$ confidence intervals were provided.

Pharmacodynamic methods. Pharmacodynamic assessments included quantitative reverse transcriptase-polymerase chain reaction (RT-PCR) assays, multianalyte immunoassay panels (MAIP) [Rules-based Medicine (Myriad RBM), Austin, TX, USA], and gene expression microarrays (Affymetrix ${ }^{\circledR}$, Santa Clara, CA, USA). Blood for serum collection was collected prior to initiation of treatment and at various times for up to 12 days following treatment. Normal blood collected from five healthy volunteers was used for bioanalytical comparison of microarray profiles between patients with disease and healthy subjects. This collection of normal blood samples was not part of the current study and was part of a previous publication (34). Additionally, CD $4{ }^{+} \mathrm{CD} 25^{+}$ $\mathrm{T}$-cell counts and total $\mathrm{T}$ cells for the lymphocyte population were monitored to evaluate immune function by standard flow cytometry. All patients undergoing PD assessments who yielded data from RT-PCR, MAIP and gene expression microarrays were included in the analyses.

RT-PCR assay of gene expression. Measurements observed with repeated qRT-PCR normalized to glyceraldehyde3 -phosphate dehydrogenase, housekeeping gene, were recorded for SMAD7, TMEPAI, OCIAD2 and CA1 and analyzed using a linear mixed model since the normality assumption was appropriate. Dose, nominal time point, and dose-by-time-point interaction were included as fixed effects, baseline (predose) value as covariate, and subject as random effect in the model, which allowed the formal pre-post dosing comparison of the gene expression. Similarly, observed percentage changes from baseline (predose) of postdose qRT-PCR measurements were analyzed with dose, nominal time point, and dose-by-time-point interaction as fixed effects, screening value as covariate, and subject as random effect, and derived model percentage changes plotted against time. The assumed covariance structure for both models was compound symmetry, which was deemed more appropriate for the data, while the degrees of freedom for the tests of fixed effects were calculated using the Kenward and Roger method.

Multianalyte immunoassay panel (MAIP). The MAIP repeated measurements data from 89 analytes were plotted over time by dose groups to which logarithmic transformation was applied, as appropriate to the data.

Affymetrix analysis. Gene-expression profiling using Affymetrix U133 microarray data was analyzed. Previously, evaluation of the effects of TGF- $\beta 1$ with cell-lines and isolated normal peripheral blood mononuclear cells (PBMCs) revealed that the difference between TGF- $\beta 1$ stimulated and unstimulated conditions was best captured by 8 genes from the array: SMAD7, CRYBB1, ATF3, TFDP2, CA1, OCIAD2, TMEPAI, and TMCC2, GAPDH was used as a normalizer. A linear mixed model with random patient effect was used to analyze the change from pre-T $\beta \mathrm{M} 1$ treatment baseline in the repeated expression measures (log scale). Nominal time point and ex vivo-based prediction of TGF- $\beta 1$ stimulated versus TGF- $\beta 1$ unstimulated at baseline were treated as fixed effects. The model LS means and p-values at nominal time points were reported. Additionally, we evaluated an extended set of 37 genes previously shown to be associated with TGF- $\beta 1$ pathway activation in the ex vivo PBMC stimulation and expression measurement assay (35). Signal values for the probe sets corresponding to the 37 genes were normalized and represented as an expression index according to Zhaou and Rocke (36).

\section{Results}

Patient disposition. A total of 18 patients entered the study and received at least 1 dose of T $\beta \mathrm{M} 1$. The majority of patients were treated for 2 cycles $(n=14)$. Among the reasons for discontinuation, the most common reason was progressive disease $(n=16)$. One patient died from his bladder cancer during the study and 1 patient discontinued per own decision.

The second dose cohort $(60 \mathrm{mg})$ was expanded to a total of 8 patients due to a grade 3 diarrhea DLT in one of the initial 3 participants. Following confirmation that there were no additional DLTs and assessment of the systemic exposure and safety information, the study continued with escalation up to the predefined 240-mg dose.

Patient demographics, disease characteristics and disposition. The patient baseline demographics by T $\beta \mathrm{M} 1$ dose are described in Table I. The mean age of the patient population was 62 years. Female patients comprised 50\% $(n=9)$ of the study population. A majority of study population was Caucasian $(n=17,94 \%)$. In general, the baseline demographics were similar between the dose groups.

All 18 patients who entered the study had an ECOG performance status $\leq 2$, with the majority of patients $(n=15$, $83 \%$ ) having a score of 1 (Table I). Six patients (33\%) had an initial pathological diagnosis of adenocarcinoma of colon, $3(17 \%)$ had adenocarcinoma of rectum, and $2(11 \%)$ had not-otherwise-specified sarcoma. The 7 remaining patients (39\%) each had unique cancer diagnoses. 
Table I. Patient demographics and disease characteristics of all enrolled and treated patients by dose.

\section{Part A}

\begin{tabular}{|c|c|c|c|c|c|}
\hline Parameter & $20 \mathrm{mg}, \mathrm{N}=3$ & $60 \mathrm{mg}, \mathrm{N}=8$ & $120 \mathrm{mg}, \mathrm{N}=3$ & $240 \mathrm{mg}, \mathrm{N}=4$ & Total, $\mathrm{N}=18$ \\
\hline \multicolumn{6}{|l|}{ Age, years } \\
\hline Mean (SD) & $73 \quad(7.6)$ & 61 (20.7) & $61(12.1)$ & $57(15.5)$ & $62(16.5)$ \\
\hline Median (range) & $75(65,80)$ & $71(23,81)$ & $65(47,70)$ & $53(43,79)$ & $68(23,81)$ \\
\hline \multicolumn{6}{|l|}{ Gender, n (\%) } \\
\hline Female & $2 \quad(67)$ & $4 \quad(50)$ & $1 \quad(33)$ & $2 \quad(50)$ & $9 \quad(50)$ \\
\hline Male & $1 \quad(33)$ & $4 \quad(50)$ & $2 \quad(67)$ & $2 \quad(50)$ & $9 \quad(50)$ \\
\hline \multicolumn{6}{|l|}{ Race, n (\%) } \\
\hline Caucasian & $3(100)$ & $8 \quad(100)$ & $2 \quad(67)$ & 4 (100) & $17 \quad(94)$ \\
\hline African American & $0 \quad(0)$ & $(0)$ & $1 \quad(33)$ & $(0)$ & (6) \\
\hline \multicolumn{6}{|l|}{ ECOG PS, n (\%) } \\
\hline 0 & $(0)$ & $1 \quad(13)$ & $1 \quad(33)$ & $1 \quad(25)$ & $3 \quad(17)$ \\
\hline 1 & $3(100)$ & $7 \quad(88)$ & $2 \quad(67)$ & $3 \quad(75)$ & $15 \quad(83)$ \\
\hline \multicolumn{6}{|c|}{ Basis of initial pathological diagnosis, $\mathrm{n}(\%)$} \\
\hline Histopathological & $3(100)$ & $7 \quad(88)$ & $3(100)$ & $4(100)$ & $17 \quad(94)$ \\
\hline Cytological & $0 \quad(0)$ & $1 \quad(13)$ & $(0)$ & $(0)$ & $(6)$ \\
\hline \multicolumn{6}{|c|}{ Initial pathological diagnosis, n (\%) } \\
\hline Adenocarcinoma, colon & $2 \quad(67)$ & $2 \quad(25)$ & $2 \quad(67)$ & $(0)$ & $6 \quad(33)$ \\
\hline Adenocarcinoma, rectum & $(0)$ & $1 \quad(13)$ & $1 \quad(33)$ & $1 \quad(25)$ & $3 \quad(17)$ \\
\hline Sarcoma, NOS & $1 \quad(33)$ & $1 \quad(13)$ & $(0)$ & $(0)$ & $2 \quad(11)$ \\
\hline Other ${ }^{\mathrm{a}}$ & $(0)$ & $4 \quad(50)$ & $(0)$ & $3 \quad(75)$ & $7 \quad(39)$ \\
\hline
\end{tabular}

${ }^{a}$ Others include 1 each are: adenocarcinoma of gastric, adenocarcinoma of pancreas, carcinoma of breast, carcinoma of renal cell, carcinoma of cervix squamous cell, carcinoma of lung squamous cell, carcinoma of urothelial transitional cell. N, total enrolled and treated population; n, number of patients in the group; SD, standard deviation; ECOG PS, Eastern Cooperative Oncology Group Performance Status; NOS, not otherwise specified.

Table II. Summary of adverse events in all enrolled and treated patients by dose.

\begin{tabular}{|c|c|c|c|c|c|}
\hline & $\begin{array}{c}20 \mathrm{mg}, \mathrm{N}=3 \\
\mathrm{n}(\%)\end{array}$ & $\begin{array}{c}60 \mathrm{mg}, \mathrm{N}=8 \\
\mathrm{n}(\%)\end{array}$ & $\begin{array}{c}120 \mathrm{mg}, \mathrm{N}=3 \\
\mathrm{n}(\%)\end{array}$ & $\begin{array}{c}240 \mathrm{mg}, \mathrm{N}=4 \\
\mathrm{n}(\%)\end{array}$ & $\begin{array}{c}\text { Total, } \mathrm{N}=18 \\
\mathrm{n}(\%)\end{array}$ \\
\hline Patients with $\geq 1 \mathrm{AE}$ & $3(100)$ & $8(100)$ & $3(100)$ & $4(100)$ & $18(100)$ \\
\hline Possibly related to study drug & $2(67)$ & $4(50)$ & 1 (33) & $2(50)$ & $9(50)$ \\
\hline Patients with $\geq 1$ TEAE & $3(100)$ & $8(100)$ & $3(100)$ & $4(100)$ & $18(100)$ \\
\hline Possibly related to study drug & $2(67)$ & $4(50)$ & 1 (33) & $2(50)$ & $9(50)$ \\
\hline Patients with $\geq 1$ Grade $3 / 4$ CTCAE & $1(33)$ & $8(100)$ & $0 \quad(0)$ & $4(100)$ & $13(72)$ \\
\hline Possibly related to study drug & $0 \quad(0)$ & $1 \quad(13)$ & $0 \quad(0)$ & $1 \quad(25)$ & $2(11)$ \\
\hline Patients with $\geq 1 \mathrm{SAE}$ & $0 \quad(0)$ & $6(75)$ & $0 \quad(0)$ & $2(50)$ & $8(44)$ \\
\hline Possibly related to study drug & $0 \quad(0)$ & 1 (13) & $(0)$ & $1 \quad(25)$ & $2(11)$ \\
\hline Patients who discontinued due to $\mathrm{AE}$ & $0 \quad(0)$ & $0 \quad(0)$ & $0 \quad(0)$ & $0 \quad(0)$ & $0 \quad(0)$ \\
\hline Patients who discontinued due to SAE & $0 \quad(0)$ & $0 \quad(0)$ & $0 \quad(0)$ & $(0)$ & $0 \quad(0)$ \\
\hline
\end{tabular}

AE, adverse event; $\mathrm{N}$, total safety population size; $\mathrm{n}$, number of patients with at least one adverse event per event type; SAE, serious adverse event; TEAE, treatment-emergent adverse event.

Safety measures. Table II describes the AEs, TEAEs, CTCAE grade toxicity, SAEs and discontinuations. One patient with bladder cancer died during the study due to progressive disease and 8 reported at least 1 SAE. Two of the 8 patients $(11 \%)$ with an SAE had, in the investigator's opinion, an SAE possibly related to the study drug. None of the patients 
Table III. Pharmacokinetics parameters per dose group and per cycle reported as median (range) or geomean and CV\% when $\mathrm{n}>3$.

\begin{tabular}{|c|c|c|c|c|c|c|c|c|c|c|c|}
\hline \multirow[b]{2}{*}{ Parameter } & \multicolumn{2}{|c|}{$20 \mathrm{mg}$} & \multicolumn{3}{|c|}{$60 \mathrm{mg}$} & \multicolumn{4}{|c|}{$120 \mathrm{mg}$} & \multicolumn{2}{|r|}{$240 \mathrm{mg}$} \\
\hline & $\begin{array}{c}\text { Cycle } 1 \\
\mathrm{~N}=3\end{array}$ & $\begin{array}{c}\text { Cycle } 2 \\
\mathrm{~N}=3\end{array}$ & $\begin{array}{c}\text { Cycle } 1 \\
\mathrm{~N}=8\end{array}$ & $\begin{array}{c}\text { Cycle } 2 \\
\mathrm{~N}=4\end{array}$ & $\begin{array}{c}\text { Cycle } 3 \\
\mathrm{~N}=1\end{array}$ & $\begin{array}{c}3 \text { Cycle } 1 \\
N=3\end{array}$ & $\begin{array}{c}\text { Cycle } 2 \\
\mathrm{~N}=3\end{array}$ & $\begin{array}{c}\text { Cycle } 3 \\
\mathrm{~N}=1\end{array}$ & $\begin{array}{c}\text { Cycle } 4 \\
\mathrm{~N}=1\end{array}$ & $\begin{array}{c}\text { Cycle } 1 \\
\mathrm{~N}=4\end{array}$ & $\begin{array}{c}\text { Cycle } 2 \\
\mathrm{~N}=2\end{array}$ \\
\hline $\mathrm{T}_{1 / 2}$, (day) & $\begin{array}{c}10.50 \\
(6.30-14.00)\end{array}$ & $\begin{array}{c}11.50 \\
(7.63-13.40)\end{array}$ & $\begin{array}{c}7.63 \\
(40.51)\end{array}$ & $\begin{array}{c}8.21 \\
(18.02)\end{array}$ & 10.04 & $\begin{array}{c}8.46 \\
(50.64)\end{array}$ & $\begin{array}{c}8.88 \\
(22.30)\end{array}$ & 11.90 & 15.38 & $\begin{array}{c}7.33 \\
(8.23)\end{array}$ & $\begin{array}{c}5.67 \\
(4.83-6.54)\end{array}$ \\
\hline $\operatorname{AUC}_{0-\infty}(\mu \mathrm{g} \cdot \mathrm{h} / \mathrm{ml})$ & $\begin{array}{c}1,490 \\
(468-1,722)\end{array}$ & $\begin{array}{c}1,313 \\
(446-2,004)\end{array}$ & $\begin{array}{c}2,922 \\
(43.80)\end{array}$ & $\begin{array}{c}3,303 \\
(42.90)\end{array}$ & 2,656 & $\begin{array}{c}5,117 \\
(33.60)\end{array}$ & $\begin{array}{c}5,061 \\
(21.70)\end{array}$ & 4,889 & 6,707 & $\begin{array}{c}8,987 \\
(31.00)\end{array}$ & $\begin{array}{c}8,118 \\
(6,025-10,210)\end{array}$ \\
\hline
\end{tabular}

${ }^{a}$ Due to a less intensive sampling time, the values should not be compared with cycles 1 and $2 . \mathrm{AUC}_{0-\infty}$, area under the concentration-time curve from zero extrapolated to infinity.

Table IV. Statistical analysis of dose proportionality for $\mathrm{AUC}_{0-\infty}$.

\begin{tabular}{lccc}
\hline $\begin{array}{l}\text { PK } \\
\text { variable }\end{array}$ & $\begin{array}{c}\text { Doses } \\
\text { ratio }\end{array}$ & $\begin{array}{c}\text { Predicted geometric } \\
\text { mean PK parameter } \\
\text { values }\end{array}$ & $\begin{array}{c}\mathrm{R}_{\mathrm{dnm}} 90 \% \\
\text { confidence } \\
\text { interval }\end{array}$ \\
\hline AUC $_{0-\infty}$ & 12 & 1,112 to 9,232 & $0.69(0.41,1.17)$ \\
& 6 & & $0.77(0.52,1.12)$ \\
& 4 & & $0.81(0.61,1.09)$ \\
& 2 & & $0.90(0.78,1.04)$ \\
\hline
\end{tabular}

$\mathrm{AUC}_{0-\infty}$, area under the concentration-time curve from zero extrapolated to infinity; Cmax, maximum plasma concentration; PK, pharmacokinetics; $\mathrm{R}_{\mathrm{dnm}}$, ratio of model-predicted mean values for high and low dose, normalized for dose.

discontinued due to adverse events. Nine patients (50\%) had at least one TEAE that in the opinion of the investigators was treatment related. Regardless of CTC grade, fatigue, nausea and diarrhea were the most frequently reported possibly drugrelated TEAEs. Each of these events occurred in 3 patients, which corresponds to $17 \%$ of the treated patients.

Thirteen patients $(72 \%)$ reported at least 1 grade $3 / 4$ CTCAE toxicity (Table II). The majority of possibly drug-related TEAEs were assessed as grade 1 or 2 . Two grade 3 toxicities related to the study drug were reported including diarrhea ( $\mathrm{n}=1$ at $60 \mathrm{mg}$ in cycle 1$)$ and generalized muscle weakness ( $\mathrm{n}=1$ at $240 \mathrm{mg}$ in cycle 1$)$. No grade 4 toxicities related to the study drug were reported. The grade 3 diarrhea was both an SAE and a DLT that ultimately led to the expansion of the 60-mg group (cohort 2). The event resolved and the patient remained on the study until later discontinuation due to progressive disease. The grade 3 muscle weakness was also an SAE and the event had not resolved when the patient discontinued from the study due to patient decision and was placed in hospice care. In addition, 1 patient at the 240-mg dose level (cohort 4) had a treatment-emergent grade 2 CTCAE laboratory abnormality (low hemoglobin) that was considered, in the opinion of investigator, as a possibly studydrug-related.

There were no changes reported in vital signs with regard to temperature, heart rate, or blood pressure after administra- tion of T $\beta \mathrm{M} 1$ in any of the patients on therapy and by dose. No clinically relevant changes in ECGs were observed.

Other safety measures determined were: skin assessments, oral examinations and bone-pain assessments. One drug-related dry mouth was reported and 1 related TEAE was reported for each including intermittent lip peeling, facial ulceration and rash. All events resolved during the study.

Pharmacokinetic measures. The systemic exposure after IV administration of T $\beta \mathrm{M} 1$ is presented in Table III across 20 to $240 \mathrm{mg}$ dose ranges (cohorts 1 to 4 ). The terminal half-life $\left(\mathrm{t}_{1 / 2}\right)$ remained relatively constant (at approximately 9 days) and ranged from approximately 5.67 to 15.38 days. Following a 10 -min infusion, T $\beta$ M1 AUC increased with dose. Table IV presents the results of the statistical analysis of dose proportionality for $\mathrm{AUC}$ from zero extrapolated to infinity $\left(\mathrm{AUC}_{0-\infty}\right.$ in cycle 1) using the power model for T $\beta \mathrm{M} 1$.

Pharmacodynamic measures. While IL-2 levels were increased approximately $2 \mathrm{~h}$ after IV administration of $\mathrm{T} \beta \mathrm{M} 1$, other plasma protein were decreased or not changed after dosing of T $\beta \mathrm{M} 1$ (Fig. 1A-C). Vascular endothelial growth factor (VEGF) levels were decreased at the 60-mg and $240-\mathrm{mg}$ doses of T $\beta \mathrm{M} 1$ and basic fibroblast growth factor (bFGF) levels were also reduced at 60-mg and 240-mg doses of T $\beta \mathrm{M} 1$. These effects were seen consistently in patient cohorts.

Changes in expression of genes associated with the TGF- $\beta 1$ pathway activation have been reported to influence tumorigenesis in genetically altered animals (37). We previously observed (35) changes in global gene expression and associated a 37-gene whole blood expression profile that was associated with markers of systemic TGF- $\beta 1$-dependent pathway activation. Here, we show the measurement of whole blood expression signals for the 37 genes and their association with TGF- $\beta 1$ pathway activation status compared with whole blood from normal subjects (Fig. 2). A hierarchically clustered heat map of the corresponding probe set signals in pretreatment patient whole blood clearly separated certain patient samples from normal samples collected in Tempus tubes. In normal samples designated Tempus 18-23 (upper left region of left panel) there is a region where several genes are expressed at lower level (green) in normal subjects compared 


\section{IL-2 (pg/ml)}

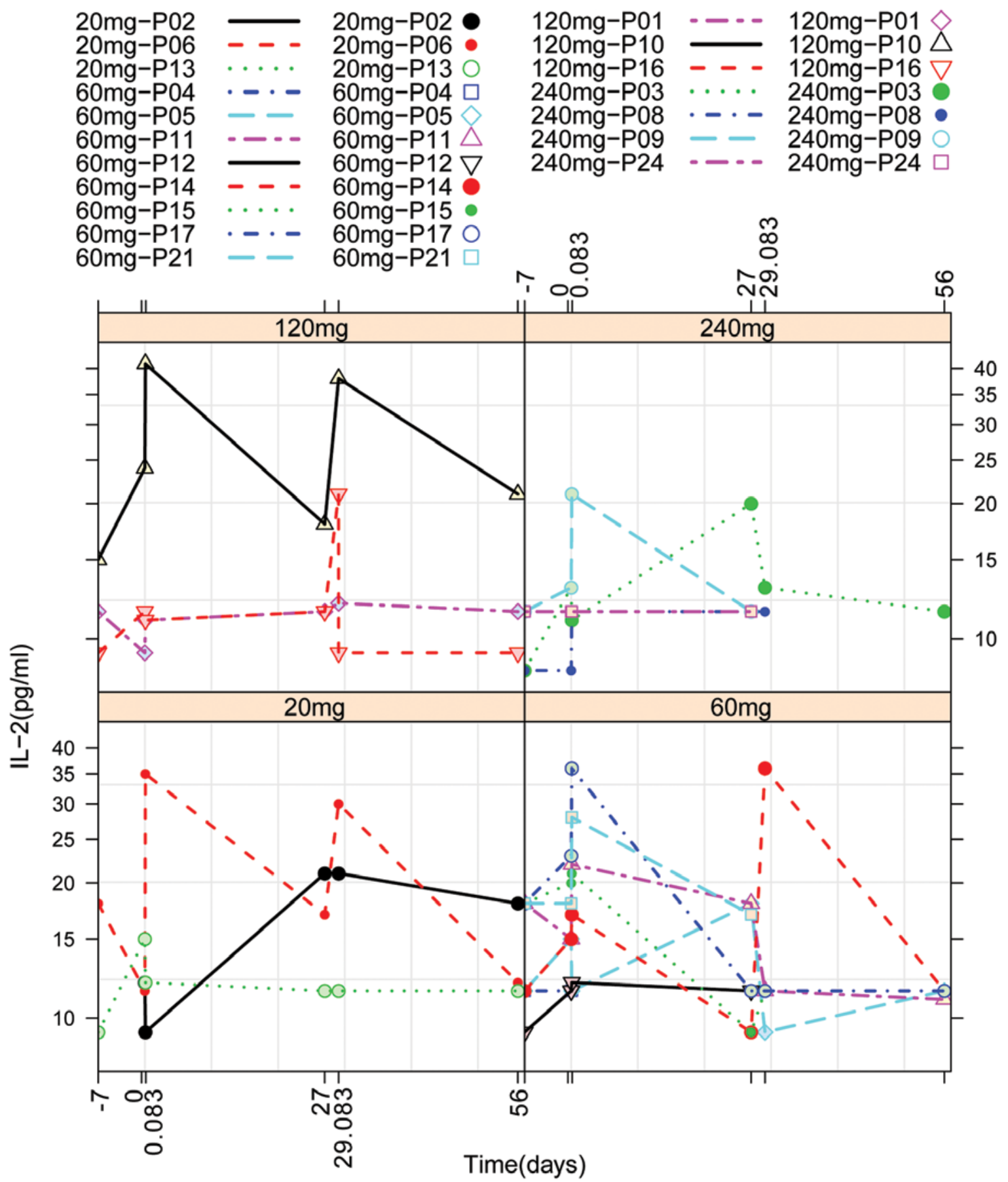

Figure 1. Individual patient profiles of multianalyte immunoassay panel test results over sampling time points. (A) Levels of IL-2 at different doses (20, 60, 120 and $240 \mathrm{mg}$ ) of T $\beta \mathrm{M} 1$. The levels of these biomarkers were measured at different time points after administration as shown on X-axis. Time point $1, \leq 7$ days prior to first dose; time point 2 , cycle 1 , predose; time point 3 , cycle $1,2 \mathrm{~h}$ post-dose; time point 4 , cycle 1,27 th day; time point 5 , cycle $2,2 \mathrm{~h}$ post-dose; time point 6 , cycle 2,27 th day.

with increasing expression (going from green to red) in patients. Similarly there is a set of genes in the lower left where expression in patient samples is higher than in normal subjects. The median expression index of the study samples from both populations of subjects represented in the box and whisker plot (Fig. 2, right panel) was almost 2-fold higher in cancer patients than normal subjects, suggesting increased systemic TGF- $\beta 1$ activation status in patients. In each case, the area in the box represents the upper and lower 75th and 25th percentile and the line within it represent the median. The upper and lower maximal values are represented by the outward directional extensions. Taken together, these data show that in cancer patients, there is a trend where the whole blood expression, represented by the calculated expression 


\section{bFGF (pg/ml)}

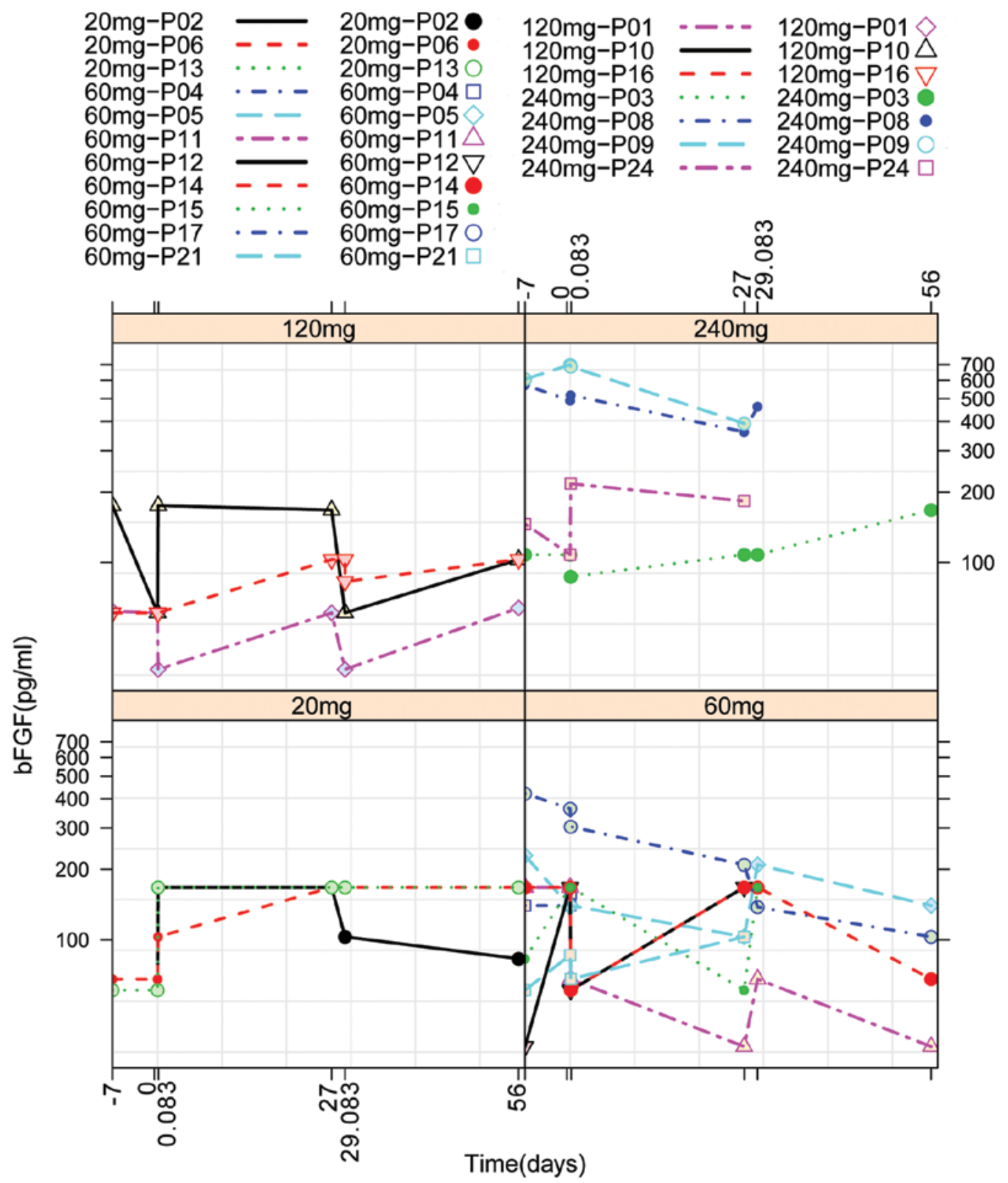

Figure 1. Continued. (B) Levels of bFGF at different doses (20, 60, 120 and $240 \mathrm{mg})$ of T $\beta$ M1. The levels of these biomarkers were measured at different time points after administration as shown on X-axis. Time point $1, \leq 7$ days prior to first dose; time point 2 , cycle 1 , predose; time point 3 , cycle 1,2 h post-dose; time point 4 , cycle 1,27 th day; time point 5 , cycle 2,2 h post-dose; time point 6 , cycle 2,27 th day.

index, is shifted toward a more activated TGF- $\beta 1$ system. We also measured the expression of selected genes known to be regulated by TGF- $\beta 1$ exposure to cultured cells and/or ex vivo peripheral blood mononuclear cells (PBMCs). Fig. 3 depicts the expression of selected genes using qRT-PCR. Of the selected genes, SMAD7, TMEPAI and OCIAD2 were normally upregulated in vitro with TGF- $\beta 1$ addition while CA1 was downregulated (data not shown). The expression of CA1 increased after T $\beta \mathrm{M} 1$ treatment, especially at the 240-mg dose (panel D). The gene expression measurement of SMAD7 and TMEPAI, both known to be negative regulators of TGF- $\beta 1$ activation, were generally negative in post-treatment especially at the highest dose, indicating reduced TGF- $\beta 1$ activation and pointing to a possible PD effect with T $\beta$ M1 treatment (panels A and B). Additionally, the level of OCIAD2 expression in whole blood appeared to be reduced upon treatment at all doses (panel C). Despite hints of a PD effect, the changes noted were not consistent across treatment groups.

Clinical efficacy measures. Clinical efficacy was a secondary objective in this study. Of 18 patients who received at least 1 dose of T $\beta \mathrm{M} 1,13$ had at least 1 postdose for tumor response. Based on RECIST response assessment, the best overall study response was stable disease for 7 patients and progressive disease for 6 patients. The tumor markers in all patients, 

VEGF $(p g / m l)$

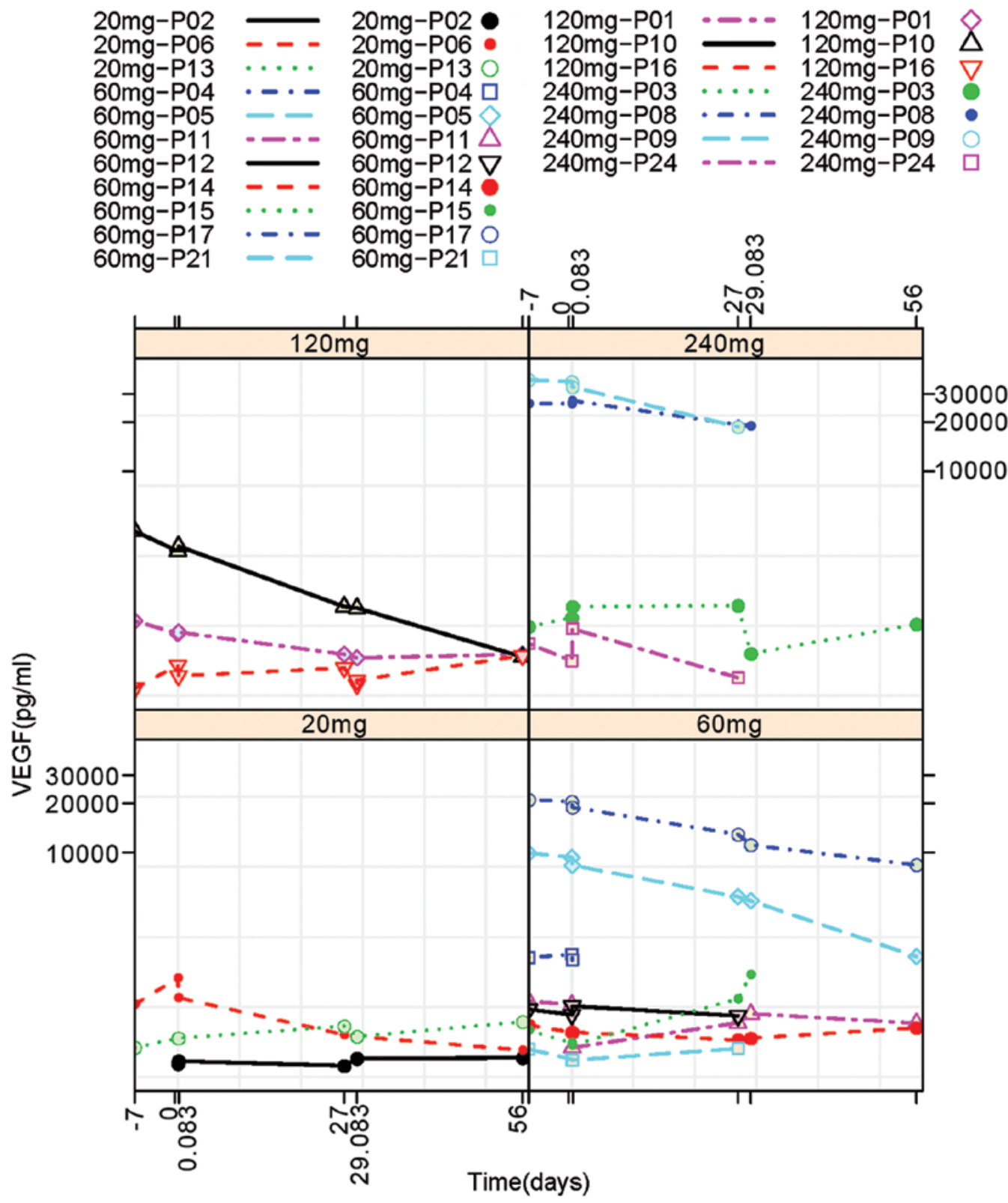

Figure 1. Continued. (C) Levels of VEGF at different doses $(20,60,120$ and $240 \mathrm{mg})$ of T $\beta \mathrm{M} 1$. The levels of these biomarkers were measured at different time points after administration as shown on X-axis. Time point $1, \leq 7$ days prior to first dose; time point 2 , cycle 1, predose; time point 3 , cycle $1,2 \mathrm{~h}$ post-dose; time point 4 , cycle 1, 27th day; time point 5, cycle 2, 2 h post-dose; time point 6, cycle 2, 27th day. IL-2, interleukin-2; bFGF, basic fibroblast growth factor; VEGF, vascular endothelial growth factor.

including lactate dehydrogenase (LDH), increased or were only briefly reduced (less than 1 cycle).

\section{Discussion}

TGF- $\beta$ inhibitors target a complex biology in cancer. Patients with advanced or metastatic conditions seem to have particularly high tumor expression, or produce large amounts of TGF- $\beta$ ligands (17). Although inhibiting only one isoform may not be sufficient to achieve antitumor efficacy, we hypothesized that targeting TGF- $\beta 1$ would be sufficient to obtain tumor responses, because it is the most prevalent ligand in plasma or serum of patients with invasive metastatic disease and correlates with adverse outcomes (8-22).

The present study was designed to evaluate the safety, PK and PD effects of T $\beta \mathrm{M} 1$ at a prespecified dose range in patients with advanced metastatic cancer. In contrast to typical phase I dose-escalation studies in oncology, the objective of this study was not to investigate a maximum tolerated dose (MTD). Given that T $\beta \mathrm{M} 1$ is hypothesized to bind and neutralize TGF- $\beta 1$ at low concentrations, it was proposed that the consequence of blocking TGF- $\beta 1$ would result in significant PD effects in cancer patients at monthly intravenous doses of 120 to $240 \mathrm{mg}$. The PD effects were expected to translate to clinical signals 


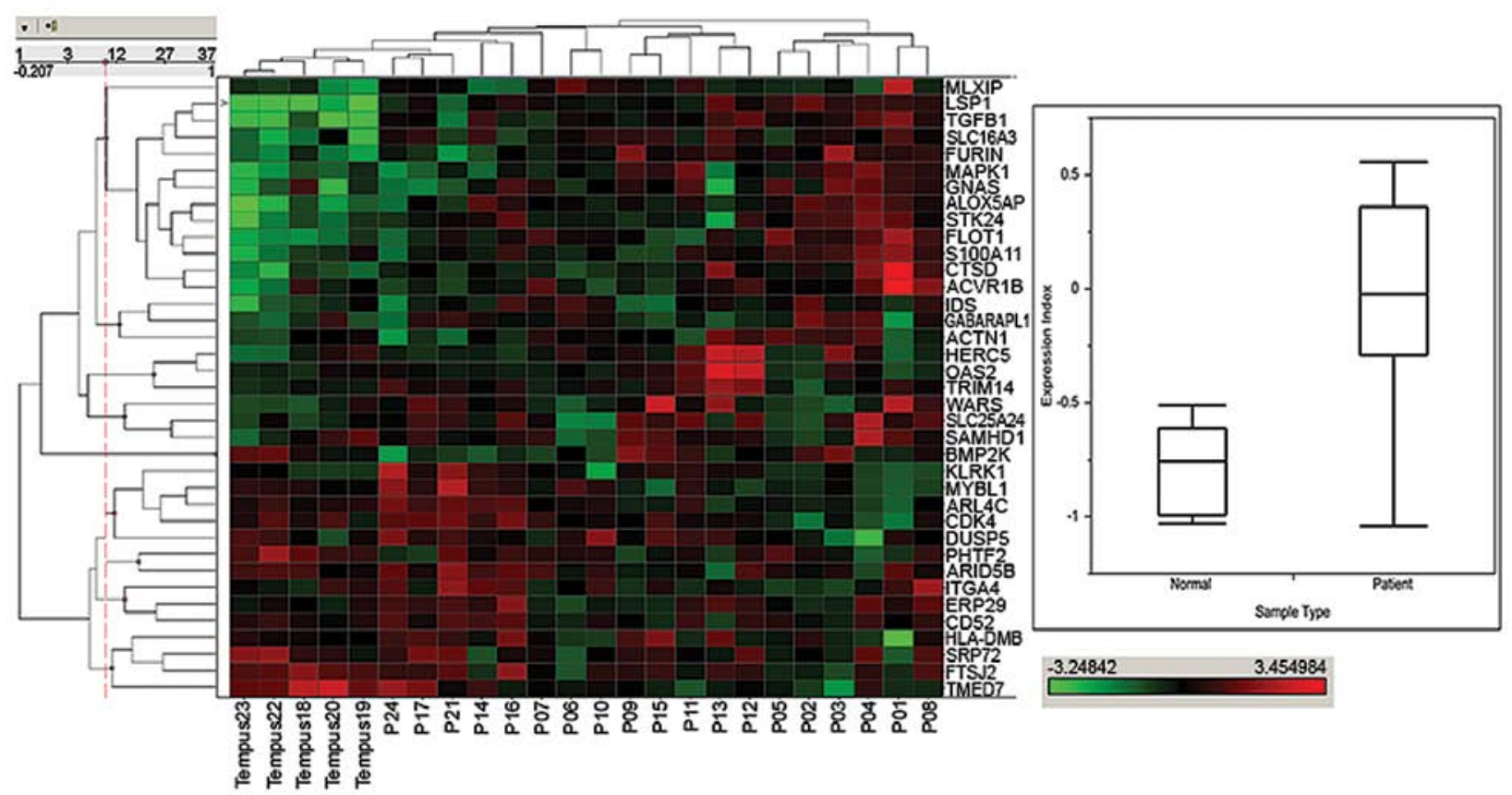

Figure 2. Hierarchical clustered heat map representation of the expression signals from 37 genes associated with systemic TGF- $\beta 1$ pathway activation (study samples are designated with an underlying blue bar). Each column represents expression signals for an individual sample for genes designated to the right. Samples designated as Tempus with an underlying green bar were from normal subjects and were used for bioanalytical comparison (samples collected from healthy subject in a previously published study). The adjacent box plot is a representation of the 37-gene calculated expression index values for normal (Tempus) samples and patient samples. The upper and lower lines of the box represent the 75th and 25th percentile and the line within the box represents the median value. The outward whiskers represent the upper and lower ranges.

A

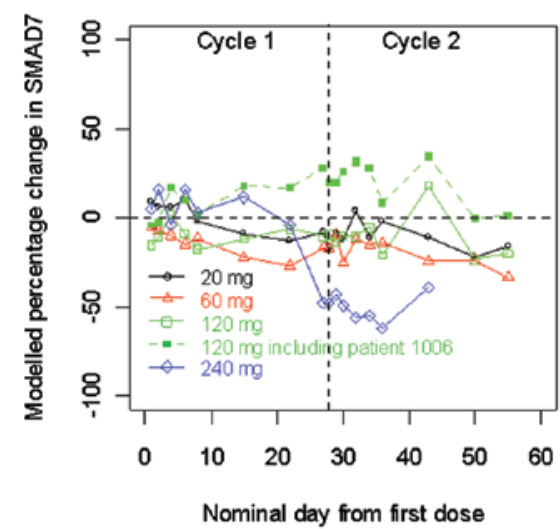

C

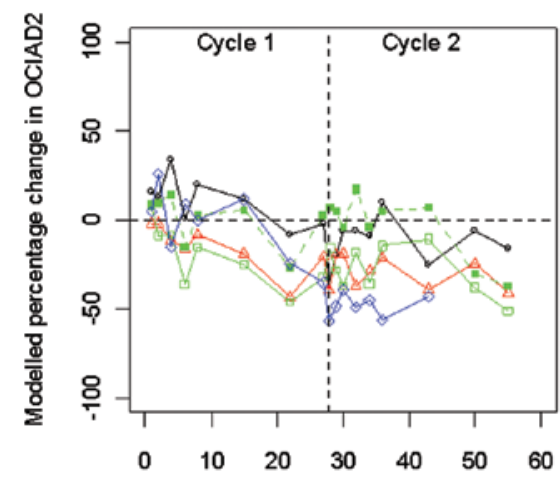

Nominal day from first dose
B

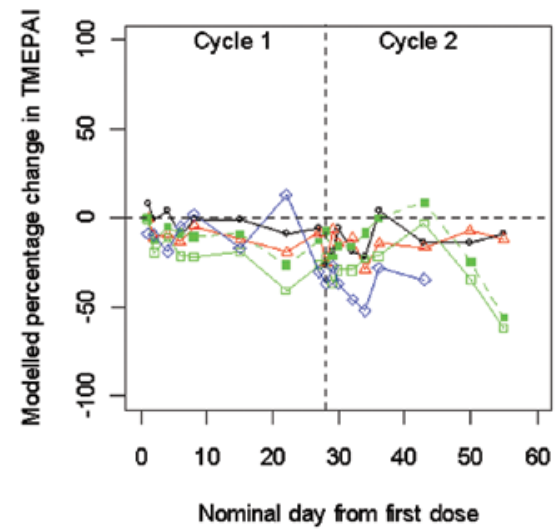

D

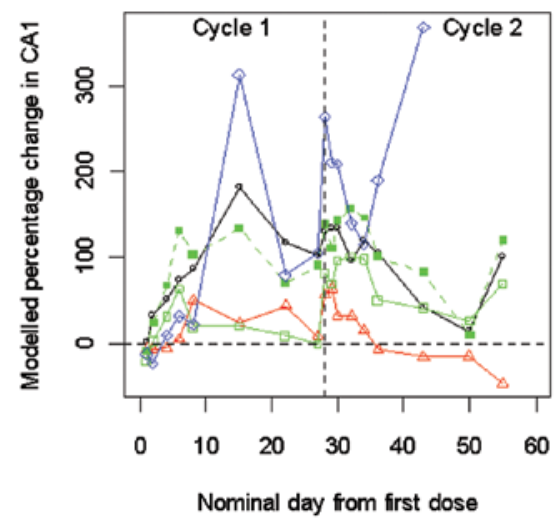

Figure 3. Change in the expression of genes as a function of dose in patient whole blood as measured by qRT-PCR analysis for T $\beta$ M1 administered over cycle 1 and cycle $2(20,60,120$ and $240 \mathrm{mg}$ ). (A) SMAD7; (B) TMEPA1; (C) OCIAD2 and (D) CA1. 
such as tumor responses, because a neutralizing mAb with a lower affinity to all three TGF- $\beta$ ligands $(32,33)$ produced antitumor responses in patients with melanoma and renal cell carcinoma (RCC) at similar doses.

Safety. Overall, T $\beta \mathrm{M} 1$ was well tolerated across the 20 to $240 \mathrm{mg}$ dose range. No pattern of a dose-response relationship with AEs was noted and no patient discontinued due to AEs or SAEs. Sixteen of the 18 cancer patients discontinued study treatment due to progressive disease. The only death was a patient in the 60-mg cohort who died due to his bladder cancer. One patient who received $240 \mathrm{mg}$ discontinued study treatment per own decision. Except for the escalation from the first to second dose cohort (20 and $60 \mathrm{mg}$, respectively), dose escalation of T $\beta \mathrm{M} 1$ preceded as planned and the only DLT identified was a self-limited grade 3 diarrhea observed in one of the initial 3 patients in the 60-mg cohort. Logistic regression analysis for the probability of experiencing a DLT was not performed, as there was only one occurrence of a DLT.

Pharmacokinetic profile of T $\beta M 1$. The PK profile is consistent with other known monoclonal antibodies (38). Since this agent is an IgG4 and is given IV, these study data provide additional information on the PK behavior of this class of mAb compared with the IgG1 and IgG2 backbone. T $\beta$ M1 measurements of anti-drug antibody (ADA) confirmed that less than $1 \%$ of the patients developed antibodies against T $\beta \mathrm{M} 1$ (one patient in this study).

Pharmacodynamics of T $\beta M 1$. The small sample size limits assessments of PD effects at individual doses. Regarding the specific gene expression panel that was previously identified to be regulated by TGF- $\beta$ inhibition (39), there was non-significant reduction of SMAD7, TMEPAI and OCIAD2 at the 240-mg dose. Significant effects might have occurred with a larger sample size, more frequent dosing or higher doses. This would suggest that the dose of T $\beta \mathrm{M} 1$ was not effective enough in blocking TGF- $\beta 1$ levels in humans to achieve a reduction in gene expression in PBMCs. Notably, there was no dose-related decrease; rather the reduction for all dose levels was similar. Hence, it is also possible that the observations for the 240-mg dose level were chance events. The comprehensive gene expression profiling also suggested that the doses were not sufficient to decrease the TGF- $\beta 1$ associated signaling as determined by the STK24 gene expression. After T $\beta \mathrm{M} 1$ administration, VEGF and bFGF were reduced in some patients as detected by the MAIP. While this indicates a possible T $\beta \mathrm{M} 1$ treatment effect, other markers of tumor progression were increased in the same and other patients. For instance, IL- 6 was increased in a patient with RCC and IL-8 was increased in 5 patients (data not shown). In addition to these pro-inflammatory markers, PAI-1 and TIMP-1 were increased (data not shown). The MAIP detects tumor markers which can be compared to standard chemistry tests. For instance, the carcinoembryonic antigen (CEA) values obtained by standard serum chemistry were correlated with the elevated CEA values detected by the MAIP. Unfortunately, as already shown in some patients with standard tumor marker evaluation, all the MAIP-based tumor markers increased during treatment with T $\beta \mathrm{M} 1$. Overall, the
MAIP panel depicts a situation that is consistent with tumor growth and not with tumor response and in some instances is expected based on previous evaluations (40).

Clinical response of $T \beta M 1$. The best clinical response in this study was stable disease. There were 4 patients who received 3 cycles and only 1 patient who was treated for 4 cycles. While this result is consistent with the benefits observed in general phase I oncology patients (41), the results on balance do not favor further clinical development of T $\beta \mathrm{M} 1$ as a treatment for non-specific types of cancer. The tumor markers in all patients, including lactate dehydrogenase levels, increased or were only briefly reduced (less than 1 cycle). All this suggests that the TGF- $\beta 1$ blockade by the dosing regimens employed was either inadequate, that TGF- $\beta 1$ is not sufficiently active in tumor growth, or that its inhibition leads to activation of other pro-growth pathways in patients where the relevance of TGF- $\beta$-dependent growth has not been predetermined at study entry. Compared with the fresolimumab (GC-1008) clinical observation, another IgG4 mAb but directed against all 3 ligands (32), it is possible that T $\beta \mathrm{M} 1$ may have been active in patients with melanoma. However, no melanoma patients were included in this study.

In summary, T $\beta \mathrm{M} 1$ is safe when administered once monthly by IV for $10 \mathrm{~min}$. No MTD was observed. Reduction in PD marker levels of VEGF and bFGF suggests minor activity of T $\beta \mathrm{M} 1$ on the targeted pathway at the dose regimens investigated. PD effects on gene expression profiles do not translate into significant antitumor effects in patients. This lack of a consistent PD response and a clinical antitumor effect in the various cancers included in this trial failed to identify a tumor type responsive to isolated TGF- $\beta 1$ suppression that warrants further study.

\section{Acknowledgements}

This study was sponsored by Eli Lilly and Company, IN, USA. The authors wish to express their appreciation to investigators, coordinators and patients for their participation in this study. Dr M. Lahn, Dr D. Desaiah and Ms. K. Williams are employees of Eli Lilly and Company, Indianapolis, IN, USA and hold company stock. Ms. A. Cleverly and Ms. C. Pitou are employees of Eli Lilly and Company, Windlesham, Surrey, UK and hold company stock options. Dr A. Cohn, Dr P. Conkling, Dr R. Raju and Dr D. Richards have no financial disclosures.

\section{References}

1. Massagué J: TGF $\beta$ signal transduction. Annu Rev Biochem 67: 753-791, 1998.

2. Muraoka-Cook RS, Dumont N and Arteaga CL: Dual role of transforming growth factor beta in mammary tumorigenesis and metastatic progression. Clin Cancer Res 11: 937s-943s, 2005.

3. Sun L: Tumour-suppressive and promoting function of transforming growth factor beta. Front Biosci 9: 1925-1935, 2004.

4. De Caestecker MP, Piek E and Robers AB: Role of transforming growth factor-beta signaling in cancer. J Natl Cancer Inst 92: 1388-1402, 2000.

5. Park BJ, Park JI, Byun DS, Park JH and Chi SG: Mitogenic conversion of transforming growth factor-betal effect by oncogenic Ha-Ras-induced activation of the mitogen-activated protein kinase-signaling pathway in human prostate cancer. Cancer Res 60: 3031-3038, 2000. 
6. Chen YG, Hata A, Lo RS, Wotton D, Shi Y, Pavletich N and Massagué J: Determinants of specificity in TGF-beta signal transduction. Genes Dev 12: 2144-2152, 1998.

7. Siegel PM, Shu W, Cardiff RD, Muller WJ and Massagué J: Transforming growth factor beta signaling impairs neuinduced mammary tumorigenesis while promoting pulmonary metastasis. Proc Natl Acad Sci USA 100: 8430-8435, 2003.

8. Adler H, McCurdy M, Kattan M, Timme T, Scardino P and Thompson T: Elevated levels of circulating interleukin- 6 and transforming growth factor-beta 1 in patients with metastatic prostatic carcinoma. J Urol 161: 182-187, 1999.

9. Shariat SF, Shaler M, Menesses-Diaz A, Kim IY, Kattan MW, Wheeler TM and Slawin KM: Preoperative plasma levels of transforming growth factor $\beta-1$ (TGF- $\beta 1$ ) strongly predict progression in patients undergoing radical prostatectomy. J Clin Oncol 19: 2856-2864, 2001.

10. Shariat SF, Kattan MW, Traxel E, Andrews B, Zhu K, Wheeler TM and Slawin KM: Association of pre- and postoperative plasma levels of transforming growth factor beta (1) and interleukin 6 and its soluble receptor with prostate cancer progression. Clin Cancer Res 10: 1992-1999, 2004.

11. Kattan M, Shariat SF, Andrews B, et al: The addition of interleukin-6 soluble receptor and transforming growth factor-beta1 improves a preoperative nomogram for predicting biochemical progression in patients with clinically localized prostate cancer. J Clin Oncol 21: 3573-3579, 2003.

12. Kakehi $\mathrm{Y}$, Oka H, Mitsumori $\mathrm{K}$, Itoh $\mathrm{N}$, Ogawa $\mathrm{O}$ and Yoshida O: Elevation of serum transforming growth factor- $\beta 1$ level in patients with metastatic prostate cancer. Urol Oncol 2: $131-135,1996$

13. Ivanovic V, Melman A, Davis-Joseph B, Valcic M and Geliebter J: Elevated plasma levels of TGF-beta 1 in patients with invasive prostate cancer. Nat Med 1: 282-284, 1995.

14. Kong F, Jirtle RL, Huang DH, Clough RW and Anscher MS: Plasma transforming growth factor-betal level before radiotherapy correlates with long term outcome of patients with lung carcinoma. Cancer 86: 1712-1719, 1999.

15. Kong FM, Anscher MS, Murase T, Abbott BD, Iglehart JD and Jirtle RL: Elevated plasma transforming growth factor-beta 1 levels in breast cancer patients decrease after surgical removal of the tumor. Ann Surg 222: 155-162, 1995.

16. Kong FM, Washington MK, Jirtle RL and Anscher MS: Plasma transforming growth factor-beta 1 reflects disease status in patients with lung cancer after radiotherapy: a possible tumor marker. Lung Cancer 16: 47-59, 1996

17. Lahn M, Berry B, Kloeker S and Yingling J: TGF- $\beta$ receptor kinase inhibitors for the treatment of cancer. In: Smad Signal Transduction: Smads in Proliferation, Differentiation and Disease. Ten Dijke P and Heldin C-H (eds). Springer-Verlad, New York, NY, pp415-442, 2006.

18. Shim KS, Kim KH, Han WS and Park EB: Elevated serum levels of transforming growth factor-beta 1 in patients with colorectal carcinoma: its association with tumor progression and its significant decrease after curative surgery resection. Cancer 85: 554-561, 1999.

19. Sheen-Chen SM, Chen HS, Sheen CW, Eng HL and Chen WJ Serum levels of transforming growth factor beta 1 in patients with breast cancer. Arch Surg 136: 937-940, 2001.

20. Tsushima $\mathrm{H}$, Ito $\mathrm{N}$, Tamura $\mathrm{S}$, et al: Circulating transforming growth factor betal as a predictor of liver metastasis after resection in colorectal cancer. Clin Cancer Res 7: 1258-1262, 2001.

21. Barthelemy-Brichant N, David JL, Bosquee L, et al: Increased TGF-beta 1 plasma level in patients with lung cancer: potential mechanisms. Eur J Clin Invest 32: 193-198, 2002

22. Xiong B, Yuan HY, Hu MB, Zhang F, Wei ZZ, Gong LL and Yang GL: Transforming growth factor-beta1 in invasion and metastasis in colorectal cancer. World J Gastroenterol 8: 674-678, 2002.
23. Hau P, Bogdahn U, Stauder G, Kunst $\mathrm{M}$ and Schlingensiepen $\mathrm{KH}$ TGF- $\beta 2$ specific antisense oligonucleotide (AP-12009) as continuous intratumoural treatment of recurrent high-grade glioma patients. Arzneim-Forsch Drug Res 53: 464, 2003.

24. Dvorchik BH: The disposition (ADME) of antisense oligonucleotides. Curr Opin Mol Ther 2: 253-257, 2000.

25. Sawyer JS, Anderson BD, Beight DW, et al: Synthesis and activity of new aryl- and heteroaryl-substituted pyrazole inhibitors of the transforming growth factor-beta type I receptor kinase domain. J Med Chem 46: 3953-3956, 2003.

26. Yingling JM, Blanchard KL and Sawyer JS: Development of TGF-beta signaling inhibitors for cancer therapy. Nat Rev Drug Discov 3: 1011-1022, 2004.

27. Robinson S, Pool R and Giffin R: Forum on Drug Discovery, Development, and Translation: Emerging Safety Science: Workshop Summary. National Academies Press, Washington, DC, 2008

28. Lonning S, Mannick J and McPherson JM: Antibody targeting of TGF- $\beta$ in cancer patients. Curr Pharm Biotechnol 12: 2176-2189, 2011

29. Gatto B: Monoclonal antibodies in cancer therapy. Curr Med Chem Anticancer Agents 4: 411-414, 2004.

30. Muraoka RS, Dumont N, Ritter CA, et al: Blockade of TGF- $\beta$ inhibits mammary tumor cell viability, migration, and metastases. J Clin Invest 109: 1551-1559, 2002.

31. Yang Y, Dukhanina O, Tang B, et al: Lifetime exposure to a soluble TGF- $\beta$ antagonist protects mice against metastasis without adverse side effects. J Clin Invest 109: 1607-1615, 2002.

32. Morris JC, Shapiro GI, Tan AR, et al: Phase I study of GC1008: A human anti-transforming growth factor-beta (TGF $\beta$ ) monoclonal antibody (MAb) in patients with advanced malignant melanoma (MM) or renal cell carcinoma (RCC). J Clin Oncol 26: $9028,2008$.

33. Trachtman H, Fervenza FC, Gipson DS, et al: A phase 1, single-dose study of fresolimumab, an anti-TGF- $\beta$ antibody, in treatment-resistant primary focal segmental glomerulosclerosis. Kidney Int 79: 1236-1243, 2011.

34. O'Brien PJ, Ramanathan R, Yingling JM, et al: Analysis and variability of TGF-beta measurements in cancer patients with skeletal metastases. Biologics 2: 563-569, 2008.

35. Kadam S, Cleverly AL, Farmen M, et al: A canonical transforming growth factor beta-dependent signaling pathway is present in peripheral blood cells of cancer patients with skeletal metastasis. J Mol Biomark Diagn 4: 153, 2005.

36. Zhaou L and Rocke DM: An expression index for Affymetrix GeneChips based on the generalized logarithm. Bioinformatics 21: 3983-3969, 2005.

37. Kang Y, Mariano JM, Angdisen J, Moody TW, Diwan BA, Wakefield LM and Jakowlew SB: Enhanced tumorigenesis and reduced transforming growth factor- $\beta$ type II receptor in lung tumors from mice with reduced gene dosage of transforming growth factor-beta1. Mol Carcinog 29: 112-126, 2000.

38. Lobo ED, Hansen RJ and Balthsar JP: Antibody pharmacokinetics and pharmacodynamics. J Pharmacol Sci 93: 2645-2668, 2004.

39. Classen S, Muth C, Debey-Pascher S, et al: Application of $\mathrm{T}$ cell-based transcriptomics to identify three candidate biomarkers for monitoring anti-TGF- $\beta$ R therapy. Pharmacogenet Genomics 20: 147-156, 2010.

40. Baselga J, Rothenberg ML, Tabernero J, et al: TGF- $\beta$ signalling related markers in cancer patients with bone metastasis, Biomarkers 13: 217-236, 2008.

41. Horstmann E, McCabe MS, Grochow L, et al: Risks and benefits of phase 1 oncology trials, 1991 through 2002. N Engl J Med 352: 895-904, 2005 